\title{
Depth Profiling of Acrylate Copolymer/Fluoro-Copolymer Immiscible Blends
}

\author{
Yoshihisa Kano, Saburo Akiyama, Tomoyuki Kasemura,* \\ and Shigehiko KoBAYASHI** \\ Laboratory of Chemistry, Faculty of General Education, Tokyo University of Agriculture and Technology, \\ 3-5-8, Saiwai-cho, Fuchu-shi, Tokyo 183, Japan \\ * Department of Applied Chemistry, Fuculty of Engineering, Gifu University, \\ 1-1, Yanagido, Gifu-shi, Gifu 501-11, Japan \\ ** Analytical Instruments Division, Nippon Bio-Rad Laboratories, \\ 1-14-11, Shinkitano, Yodogawa-ku, Osaka 532, Japan
}

(Received August 29, 1994)

\begin{abstract}
In immiscible blends of poly(2-ethylhexyl acrylate-co-acrylic acid-co-vinyl acetate) $\mathrm{P}(2 \mathrm{EHA}-\mathrm{AA}-\mathrm{VAc}$ ) with poly(vinylidene fluoride-co-hexafluoroacetone) P(VDF-HFA), depth profiling was carried out by PAS-FTIR and ATR-FTIR analyses. Integrated surface excesses of P(VDF-HFA) component $\left(\phi_{1}\right)$ in blends were plotted against depth for P(2EHA-AA-VAc)/ $\mathrm{P}\left(\right.$ VDF-HFA) (50/50), (30/70), and (10/90) blends. In all blends, since $\phi_{1}$ decreased with increasing depth, it was expected that P(2EHA-AA-VAc)/P(VDF-HFA) blends would be gradient materials (surface segregation structures). Furthermore, at a few nm depth from the surface, XPS analysis was done to get more detailed information of the surface. We point out that PAS-FTIR is very effective analysis to get depth profiling in such immiscible polymer blends as $\mathrm{P}$ (2EHA-AA-VAc)/ P(VDF-HFA).

KEY WORDS PAS-FTIR / ATR-FTIR / XPS / Depth Profiling / Blends / Acrylate Copolymer / Fluoro-copolymer / Integrated Surface Excess /
\end{abstract}

If polymer blends consist of two components with different surface tensions, surface segregation structures or gradient materials could be formed. We thought that the appearance of surface segregation and gradient material ${ }^{1,2}$ in blend is correlated with miscibility, surface tension, density, rate of solvent casting and convection in solution. The surfaces of these materials exhibit characteristic surface properties, such as adhesion, water repellent and lubrication. The depth of a few $\mathrm{nm}$ from the surface on sample can be detected by means of X-ray photoelectron spectroscopy (XPS), ${ }^{3}$ secondary ion mass spectrometry (SIMS), ${ }^{4}$ ion scattering spectroscopy (ISS), ${ }^{5}$ neutron reflectivity (NR) ${ }^{6}$ and forward recoil spectrometry. ${ }^{7}$ On the other hand, it is well known that attenuated total reflection fourier transform infrared spectroscopy (ATR-FTIR) ${ }^{8}$ can determine a depth of $0.5 \sim 3 \mu \mathrm{m}$ from the surface. Cowie et al. ${ }^{8}$ studied surface segregation in miscible polystyrene/poly(vinyl methyl ether) blends using ATR-FTIR.

For poly(2-ethylhexyl acrylate-co-acrylic acid-co-vinyl acetate) [P(2EHA-AA-VAc)]/ poly(vinylidene fluoride-co-hexafluoroacetone) $[\mathrm{P}(\mathrm{VDF}-\mathrm{HFA})](50 / 50 \mathrm{wt}$ ratio) blend in our previous studies, ${ }^{1,9}$ we found that P(VDF-HFA) component enriched on surface and $\mathrm{P}(2 \mathrm{EHA}-\mathrm{AA}-\mathrm{VAc})$ component precipitated at bottom (contact with substrate: poly(dimethylsiloxane) coated onto paper) by using ATR-FTIR and XPS analyses. Since the fraction of P(VDF-HFA) component decreased with increasing depth (sample thickness: $30 \mu \mathrm{m}$ ), we judged that this blend would show a surface segregation or a functional gradient structure.

In general, acrylate copolymers having lower $T_{\mathrm{g}}\left(<-20^{\circ} \mathrm{C}\right)$ and possessing flexibility at 
room temperature are used as pressure sensitive adhesives (PSA). Thus, we evaluated tackiness for P(2EHA-AA-VAc)/P(VDF-HFA) blends. ${ }^{9}$ Tackiness of the surface was smaller than that of bottom in P(2EHA-AA-VAc)/ P(VDF-HFA) blends. Consequently, we expect that these blends could be used as new type PSA tapes, without backing film.

Finally, we examined the effects of miscibility, surface tension and density on surface segregation of $\mathrm{P}(2 \mathrm{EHA}-\mathrm{AA}-\mathrm{VAc}) / \mathrm{P}(\mathrm{VDF}-$ HFA) blends. The immiscibility of P(2EHAAA-VAc)/P(VDF-HFA) blends was determined by differential scanning calorimetry (DSC) and thermo-photometry. Immiscibility was also predicted by Prigogine-FloryPatterson's equation of state. The surface tension $\gamma$ of P(VDF-HFA) was smaller than that of P(2EHA-AA-VAc), while the density of P(VDF-HFA) was larger than that of P(2EHA-AA-VAc). Therefore, we point out that surface enrichment for the P(VDF-HFA) component in $\mathrm{P}(2 \mathrm{EHA}-\mathrm{AA}-\mathrm{VAc}) / \mathrm{P}(\mathrm{VDF}-$ HFA) blends is influenced by differences in $\gamma$ between components and immiscibility of two polymers.

ATR-FTIR analysis can only detect a depth of $1 \sim 2 \mu \mathrm{m}$ from surface. Dittmar et al. ${ }^{10}$ reported that step-scan FTIR with photoacoustic (PAS-FTIR) analysis could be detected for depth profiling of polymer laminates. Step-scan FTIR gives depth profile information due to single modulation frequency that can be applied over all spectral range. As a single modulation is used in step-scan FTIR, detected depth (thermal diffusion length: $\mu$ ) obtained by PAS-FTIR is constant for all wavelengths. Dittmar et al. ${ }^{10}$ also pointed out that depth $\mu$ in polymers, such as polypropylene and teflon, was about $6 \sim 16 \mu \mathrm{m}$ from the surface at $100 \sim 800(\mathrm{~Hz})$ region of modulation frequency. We noted the detected depth obtained by PAS-FTIR method is more deeper than that by ATR-FTIR method. We thus confirmed that PAS-FTIR is very effective to obtain accurately the depth profiles of gradient structures found in immiscible $\mathrm{P}$ (2EHA-AAVAc)/P(VDF-HFA) blends.

In this study, depth profiles of $\mathrm{P}(2 \mathrm{EHA}-\mathrm{AA}$ VAc)/P(VDF-HFA) (50/50), (30/70), and (10/90) blends were obtained using PAS-FTIR and ATR-FTIR data. ${ }^{11}$ At a few nm depth from the surface, depth profiles using XPS results were also constructed for these blends. Finally, XPS results were compared with those of FTIR.

\section{EXPERIMENTAL}

\section{Materials}

P(2EHA-AA-VAc) was prepared by solution polymerization at $70^{\circ} \mathrm{C}$ for $7 \mathrm{~h}$, using benzoyl peroxide as the initiator. Mixtures of ethyl acetate $(95 \mathrm{wt} \%)$ with toluene $(5 \mathrm{wt} \%)$ were used as solvents. P(VDF-HFA) was supplied by Central Glass Co., Ltd. (Japan). Compositions and molecular weights of the copolymers are shown in Table I. Molecular weights of copolymers were found using a Toso Co., Ltd. CP8000 GPC system in $0.1 \mathrm{wt} \%$ tetrahydrofuran (THF) solution.

Blend samples at various weight ratios were prepared by the knife coating system at $90^{\circ} \mathrm{C}$ for $60 \mathrm{~s}$, in which $20 \mathrm{wt} \%$ THF solutions were coated onto the release liner [dimethyl siloxane polymer having the critical surface tension $\gamma_{\mathrm{C}} \sim 24 \mathrm{dyn} \mathrm{cm}^{-1}$ is coated onto liner]. The films were seasoned at $23 \pm 3^{\circ} \mathrm{C}$ and $65 \pm$ $5 \% \mathrm{RH}$ for 7 days to produce a dry coating films $30 \mu \mathrm{m}$ in thickness. The surfaces of blend samples were covered by the release liner.

Table I. Components and molecular weights ${ }^{\mathrm{a}}$ of copolymers

$\begin{array}{ll}\text { P(2EHA-AA-VAc) } & \text { 2-Ethylhexyl acrylate/acrylic } \\ & \text { acid/vinyl acetate }=85 / 5 / 10(\mathrm{~mol} \%) \\ & M_{n}=46000, M_{w}=315000 \\ \text { P(VDF-HFA) } & \text { Vinylidene fluoride/hexafluoro } \\ & \text { acetone }=91.6 / 8.4(\mathrm{~mol} \%) \\ & M_{n}=78000, M_{w}=200000\end{array}$

a Molecular weight equivalent to that of polystyrene by GPC. 
Residual THF in blend samples could not be observed by a gas detector.

\section{Measurements}

FTIR spectra of bulk for P(2EHA-AAVAc)/P(VDF-HFA) blends were investigated by the $\mathrm{KBr}$-tablet method. The $\mathrm{KBr}$-tablet and ATR-FTIR methods were measured with Nicolet Co., Ltd. 20SXB-FTIR spectrometer. ATR-FTIR spectra were detected with KRS-5 as a prism at incidence angles of $30^{\circ}, 45^{\circ}$, and $60^{\circ}$.

Inphase and quadrature PAS-FTIR spectra of blends were obtained by Bio-Rad Laboratories step-scan FTIR spectroscopy type FTS60A/896 at $400 \mathrm{~Hz}$ as modulation frequency. The PAS cell was MTEC Co. Ltd. type 200 photoacoustic detector and regeneration of modulation signals were performed with a Bio-Rad Laboratories Demodulator. ${ }^{12}$ The inphase PAS-FTIR spectrum was defined as the phase angle at which the PAS signal is maximum. The quadrature PAS-FTIR spectra were obtained as the phase separating $90^{\circ}$ from the inphase spectra. It is well known that the measuring depth obtained by inphase PASFTIR is more deeper than that by quadrature PAS-FTIR.

XPS analysis of surface of P(2EHA-AAVAc)/P(VDF-HFA) (30/70) and (10/90) blends was performed using a Shimadzu Manufacturing Ltd. ESCA model $850 \mathrm{X}$-ray photo-electron spectrometer (X-ray voltage: $8 \mathrm{kV}$, current: $30 \mathrm{~mA}$ ), with take-off angles of $15^{\circ}, 45^{\circ}$, and $90^{\circ}$. Since fluoride is an insulator, charge correction was carried out as the peak of $F_{1}$ appears at $689 \mathrm{eV}$. XPS data for the P(2EHAAA-VAc)/P(VDF-HFA) $(50 / 50)$ blend was reused as the results measured in our previous study. ${ }^{9}$

\section{RESULTS AND DISCUSSION}

In previous studies, ${ }^{1,11} \mathrm{KBr}-\mathrm{FTIR}$ and ATR-FTIR spectra of P(2EHA-AA-VAc) and P(VDF-HFA) were examined. The stretching

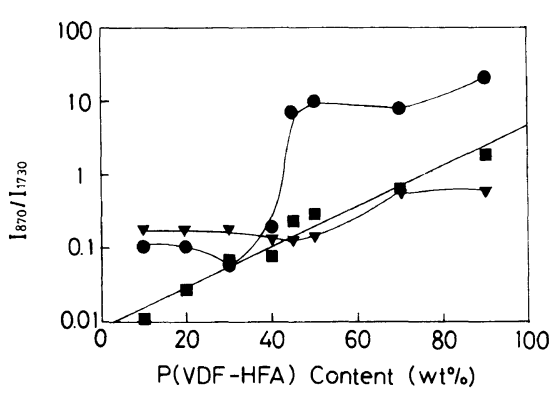

Figure 1. Relationship between absorbance ratio $\left(I_{870}\right)$ $\left.I_{1730}\right)$ and $\mathrm{P}(\mathrm{VDF}-\mathrm{HFA})$ content by $\mathrm{KBr}$-tablet and ATR-FTIR $\left(45^{\circ}\right.$ incidence angle) analyses. $\mathbf{\square}, \mathrm{KBr}$ tablet (bulk); O, ATR-FTIR (surface side); $\boldsymbol{\nabla}$, ATRFTIR (bottom side).

vibration absorption peaks of $\mathrm{C}-\mathrm{H}$ and $\mathrm{C}=\mathrm{O}$ groups were observed at $3000 \sim 2800 \mathrm{~cm}^{-1}$ and both 1160 and $1730 \mathrm{~cm}^{-1}$ in the spectrum of P(2EHA-AA-VAc), respectively. On the other hand, absorption peaks of C-F group were seen at 870,1200 , and $1400 \mathrm{~cm}^{-1}$. The absorbance ratio $\left(I_{870} / I_{1730}\right)$ in $\mathrm{P}(2 \mathrm{EHA}-\mathrm{AA}$ VAc)/P(VDF-HFA) blends was taken as the ratio of $\mathrm{C}=\mathrm{O}$ absorption at $1730 \mathrm{~cm}^{-1}\left(I_{1730}\right)$ for P(2EHA-AA-VAc) and C-F absorption at $870 \mathrm{~cm}^{-1}\left(I_{870}\right)$ for P(VDF-HFA) because of differences in concentrations of components. Plots of the $I_{870} / I_{1730}$ obtained by both $\mathrm{KBr}$-tablet and ATR-FTIR methods using $45^{\circ}$ as the incidence angle against P(VDH-HFA) weight fraction are shown in Figure 1. A straight line was obtained for $\mathrm{KBr}$-tablet by least square approximation as follows:

$$
\log \left(I_{870} / I_{1730}\right)=0.0275\left(\phi_{1}\right)-2.08
$$

where $\phi_{1}$ is the weight fraction of P(VDFHFA). This relationship between $I_{870} / I_{1730}$ and $\phi_{1}$ is according to a Lambert-Beer law. Thus, we can calculate the integrated surface excess as $\phi_{1}$ obtained by ATR-FTIR and PAS-FTIR analyses using eq 1. From ATRFTIR data shown in Figure $1, I_{870} / I_{1730}$ of surface are larger than those of bottom in blends with $50 \sim 90(\mathrm{wt} \%)$ P(VDF-HFA) content. It is thought that the surface enrichment of P(VDF-HFA) component occurs. There- 
fore, we should examine in more detail depth profiles of $\mathrm{P}$ (2EHA-AA-VAc)/P(VDF-HFA) $(50 / 50), \quad(30 / 70)$, and $(10 / 90)$ blends by ATR-FTIR, PAS-FTIR, and XPS analyses. On the other hand, in the range from 10 to 40 (wt \%) P(VDF-HFA) content, $I_{870} / I_{1730}$ of surface are smaller than those of bottom and all $I_{870} / I_{1730}$ do not change with P(VDF-HFA) content. We thus thought of the difference' of P(VDF-HFA) concentration between surface and bottom may be influenced by surface tension, miscibility, and density because the density of P(VDF-HFA) is larger than that of P(2EHA-AA-VAc).

In the ATR-FTIR method, the depth $\left(d_{\mathrm{P}}\right)$ was calculated as,

$$
d_{\mathrm{P}}=\lambda / 2 \pi n_{\mathrm{A}}\left(\sin ^{2} \theta-n_{\mathrm{BA}}^{2}\right)^{0.5}
$$

where $\theta$ is the incidence angle, $\pi$ the circular constant, $\lambda$ the infrared ray absorption wavelength, and $n_{\mathrm{A}}$ the refractive index of prism. The $n_{\mathrm{BA}}$ is the refractive index $n_{\mathrm{B}} / n_{\mathrm{A}}\left(n_{\mathrm{B}}\right.$, refractive index of sample). In this study, the depth $\left(d_{\mathrm{P}}\right)$ for $\mathrm{P}(2 \mathrm{EHA}-\mathrm{AA}-\mathrm{VAc}) / \mathrm{P}(\mathrm{VDF}-$ HFA) blend is $1 \mu \mathrm{m}$ at $60^{\circ}, 2 \mu \mathrm{m}$ at $45^{\circ}$ and could not be calculated because of $\sin ^{2} \theta-$ $n_{\mathrm{BA}}{ }^{2}<0$ at $30^{\circ}$ as incidence angles. ${ }^{1}$ The depth from the inphase spectrum in PAS-FTIR method is evaluated as the thermal diffusion length $\mu$ which increases with decreasing modulation frequency. $\mu$ is defined as following equation $^{10}$ :

$$
\mu=\left(\kappa / \rho \cdot C_{\mathrm{P}} \cdot \pi \cdot f\right)^{0.5}
$$

where $\kappa$ is the thermal conductivity, $\rho$ the density, $C_{\mathbf{P}}$ the heat capacity, $\pi$ the circular constant and $f$ the modulation frequency. $\mu$ from inphase spectrum was $8 \mu \mathrm{m}$ (calculated parameter: $\kappa$ and $C_{\mathbf{P}}$ are the reference values, ${ }^{10} \rho$ is the measured value ${ }^{13}$ ).

In bottom of $\mathrm{P}(2 \mathrm{EHA}-\mathrm{AA}-\mathrm{VAc}) / \mathrm{P}(\mathrm{VDF}-$ HFA) $(50 / 50)$ blend and surface of (10/90) blend, inphase and quadrature PAS-FTIR spectra are shown in Figures 2 and 3, respectively. Peaks of the $\mathrm{C}=\mathrm{O}$ and $\mathrm{C}-\mathrm{F}$ groups shown in these figures were observed in PAS-

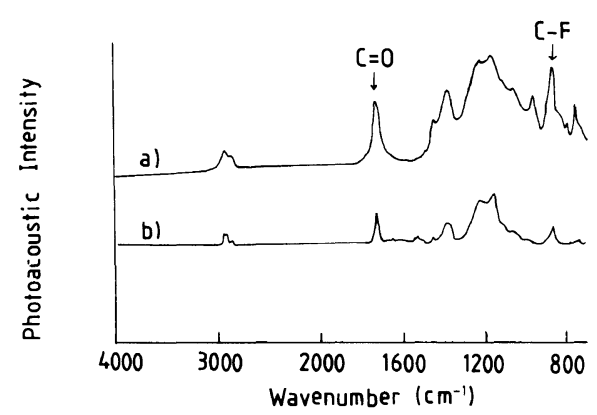

Figure 2. PAS-FTIR spectra of bottom for P(2EHAAA-VAc)/P(VDF-HFA) (50/50) blend. a) inphase; b) quadrature.

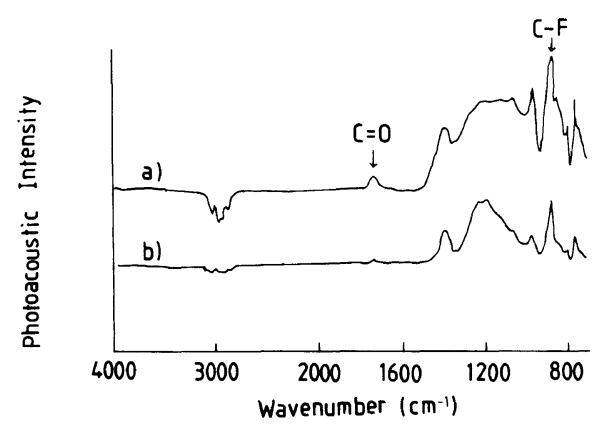

Figure 3. PAS-FTIR spectra of surface for P(2EHAAA-VAc)/P(VDF-HFA) (10/90) blend. a) inphase; b) quadrature.

FTIR spectra. The diffusion length $\mu$ of PASFTIR was deeper than the depth $d_{\mathrm{p}}$ of ATRFTIR and the $\mu$ obtained from quadrature PAS-FTIR spectrum was shorter than that from the inphase spectrum. In surface of P(2EHA-AA-VAc)/P(VDF-HFA) (10/90) blend, the peak based on the $\mathrm{C}=\mathrm{O}$ group of the inphase spectrum was larger than that of quadrature spectrum, whereas the peak based on $\mathrm{C}-\mathrm{F}$ group of inphase spectrum was smaller than that of quadrature spectrum. It is suggested that the P(VDF-HFA) weight fraction in $(10 / 90)$ blend changes from the surface to $8 \mu \mathrm{m}$ depth (air/blend). In bottom of $(50 / 50)$ blend, C-F peak for inphase spectrum was larger than that for quadrature spectrum. It is suggested that P(2EHA-AA-VAc) component in $(50 / 50)$ blend is segregated from bottom to about $8 \mu \mathrm{m}$ depth. In P(2EHA-AA-VAc)/ 
Table II. Absorbance ratios $\left(I_{870} / I_{1730}\right)$ obtained by KBr-tablet, ATR-FTIR, and PAS-FTIR methods

\begin{tabular}{ccccc}
\hline \multirow{2}{*}{$\begin{array}{c}\text { Blend } \\
\text { content } \\
\text { (wt ratio) }\end{array}$} & KBr & ATR & \multicolumn{2}{c}{ PAS } \\
\cline { 4 - 5 } \cline { 3 - 4 } $10 / 90$ & 1.9 & 20 & 14 & 7.5 \\
\hline
\end{tabular}

P(VDF-HFA) (10/90) blend, $I_{870} / I_{1730}$ obtained by $\mathrm{KBr}$-tablet, ATR-FTIR, and PASFTIR analysis are represented in Table II. $I_{870} / I_{1730}$ of $(10 / 90)$ blend decreases in the order: ATR $>$ PAS $>\mathrm{KBr}$ methods. We think that PAS-FTIR analysis is very effective for depth profiling in immiscible P(2EHA-AAVAc)/P(VDF-HFA) blends and gradient material.

We investigated the surface components of P(2EHA-AA-VAc)/P(VDF-HFA) (30/70) and $(10 / 90)$ blends by XPS analysis. XPS results of $(50 / 50)$ blend were reused as the data reported in previous study. ${ }^{9}$ XPS spectra of $\mathrm{C}_{1 \mathrm{~s}}$ at a $90^{\circ}$ take-off angle of P(2EHA-AA-VAc)/P(VDFHFA) $(10 / 90)$ blend is shown in Figure 4. In surface, the peaks of $\mathrm{CF}_{3}$ and $\mathrm{CF}_{2}$ groups were clearly observed at $295.3 \mathrm{eV}$ and $292.5 \mathrm{eV},{ }^{14}$ respectively. The peaks based on $\mathrm{CH}_{2}$ and ether group COC were observed at $286.5 \mathrm{eV}$ and $288.1 \mathrm{eV}$, respectively. We judge that the COC peak at $288.1 \mathrm{eV}$ depends on the HFA group in $\mathrm{P}$ (VDF-HFA). On the other hand, in bottom of P(2EHA-AA-VAc)/P(VDF-HFA) (10/90) blend, $\mathrm{CF}_{3}$ and $\mathrm{CF}_{2}$ peaks on XPS spectrum of $\mathrm{C}_{1 \mathrm{~s}}$ couldn't be detected. In this (10/90) blend, it was presumed that the P(VDF-HFA) component and P(2EHA-AAVAc) component are segregated at the top to a few nm depth of surface side and bottom side, respectively. This segregation for (10/90) blend was also found for (30/70) blend measured in this study and at $(50 / 50)$ blend in our previous paper. ${ }^{9}$ In general, depth $(d)$ of XPS analysis depends on the take-off angle $\theta$. Then, when $95 \%$ of signals of photoelectrons are detected at a depth $(d)$, the relationship between $d$ and $\theta$ is expressed as,
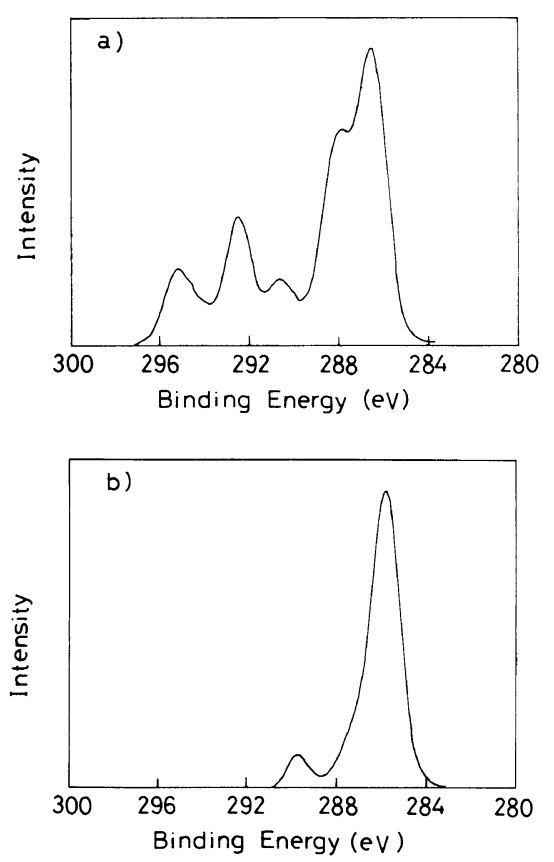

Figure 4. XPS spectra of $\mathrm{C}_{1 \mathrm{~s}}$ of $\mathrm{P}(2 \mathrm{EHA}-\mathrm{AA}-\mathrm{VAc}) /$ $\mathrm{P}(\mathrm{VDF}-\mathrm{HFA})(10 / 90)$ blend using $90^{\circ}$ as take-off angle. a) surface side; b) bottom side.

Table III. Ashley parameters for P(2EHA-AA-VAc) and $\mathrm{P}(\mathrm{VDF}-\mathrm{HFA})$

\begin{tabular}{lcrrc}
\hline \multicolumn{1}{c}{ Copolymer } & $\rho / \mathrm{g} \cdot \mathrm{cm}^{-3}$ & $M$ & $n$ & $\lambda / \mathrm{nm}\left(\mathrm{C}_{1 \mathrm{~S}}\right)$ \\
\hline P(2EHA-AA-VAc) & 0.89 & 169 & 69 & 3.55 \\
P(VDF-HFA) & 1.76 & 70 & 27 & 1.92 \\
\hline
\end{tabular}

$$
d=3 \lambda \cdot \sin \theta
$$

where $v$ is the mean free path which is calculated by Ashley's approximation ${ }^{15}$ as follows:

$$
\lambda=(M / \rho n)\left(E_{\mathrm{k}}\right) /\left(136 \cdot \ln \left(E_{\mathrm{k}}\right)-176-21000 / E_{\mathrm{k}}\right)
$$

where $M$ is molecular weight in monomer units, $\rho$ the density, $n$ the amount of valence electron and $E_{\mathrm{k}}$ the kinetic energy of photoelectron. The mean free path and Ashley parameters for $\mathrm{P}(2 \mathrm{EHA}-\mathrm{AA}-\mathrm{VAc})$ and $\mathrm{P}(\mathrm{VDF}-$ HFA) are represented in Table III. The depth of XPS analysis is about a few nm order. The differences of $\mathrm{P}(\mathrm{VDF}-\mathrm{HFA})$ weight ratio $W$ in 


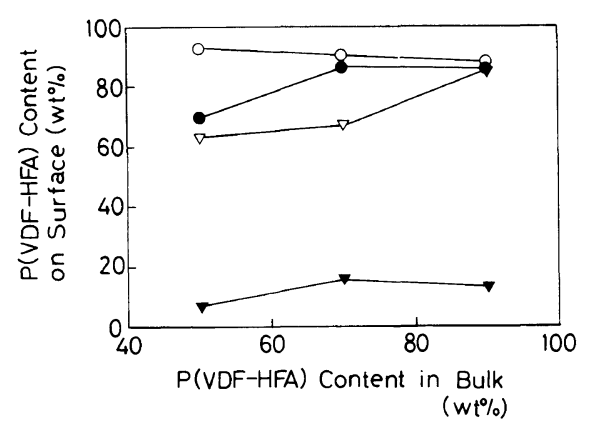

Figure 5. Relationship between $\mathrm{P}(\mathrm{VDF}-\mathrm{HFA})$ content on surface and $\mathrm{P}(\mathrm{VDF}-\mathrm{HFA})$ content in bulk for $\mathrm{P}(2 \mathrm{EHA}$ AA-VAc)/P(VDF-HFA) blends. Take-off angle: $\mathrm{O}, 15^{\circ}$; ○, $45^{\circ} ; \nabla, 90^{\circ}$ (surface side); $\nabla, 90^{\circ}$ (bottom side).

blends between surface and bulk were calculated as,

$$
\begin{aligned}
F / C= & (2.33 \cdot W / 70) /[(2.08 \cdot W / 70) \\
& +(9.05(1-W) / 157)] .
\end{aligned}
$$

The denominator and numerator exhibit the number of carbon atoms and number of fluorine atoms in each monomer. $F / C$ is the atomic ratio of fluorine $\mathrm{F}$ to carbon $\mathrm{C} . W$ is the $\mathrm{P}(\mathrm{VDF}-\mathrm{HFA})$ weight ratio at the surface in $\mathrm{P}(2 \mathrm{EHA}-\mathrm{AA}-\mathrm{VAc}) / \mathrm{P}(\mathrm{VDF}-\mathrm{HFA})$ blends. The relationship between $\mathrm{P}(\mathrm{VDF}-\mathrm{HFA})$ content at the surface and P(VDF-HFA) content in bulk for P(2EHA-AA-VAc)/P(VDF-HFA) $(50 / 50),(30 / 70)$, and $(10 / 90)$ blends is shown in Figure 5. The surface segregation of P(VDFHFA) component in these blends was confirmed by XPS analysis. P(VDF-HFA) content at surface was larger than that in bulk, while P(VDF-HFA) content at bottom was smaller than that in bulk for these blends. In the P(VDF-HFA) content at surface of P(2EHAAA-VAc)/P(VDF-HFA) (50/50), (30/70) blends, since its value decreased with increasing take-off angle, the depth profile of P(VDFHFA) concentration (integrated surface excess content $W$ ) against measuring depth could be obtained. On the other side, in the (10/90) blend, P(VDF-HFA) content at surface did not change against take-off angle. It was presumed that the P(VDF-HFA) component is remark-

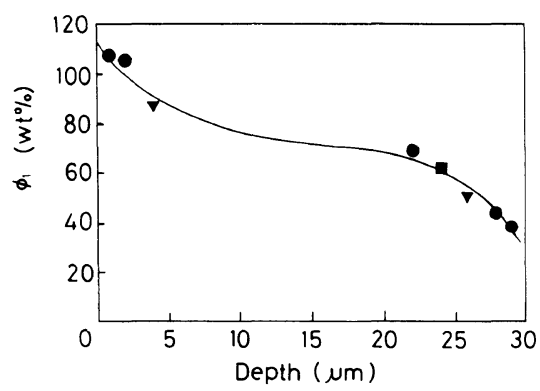

Figure 6. Depth profile of $\mathrm{P}(2 \mathrm{EHA}-\mathrm{AA}-\mathrm{VAc}) / \mathrm{P}(\mathrm{VDF}-$ HFA) $(50 / 50)$ blend obtained by ATR-FTIR and PASFTIR analyses. Integrated surface excess $\phi_{1}$ of P(VDFHFA) component versus depth calculated with eqs 2 and 3. $\phi_{1}$ were calculated by eq 1 . ATR-FTIR data with incidence angle of $60^{\circ}$ and $45^{\circ}$ and inphase PAS-FTIR data; $\nabla$, ATR-FTIR data with incidence angle of $30^{\circ} ; \mathbf{\square}$, quadrature PAS-FTIR data.

ably segregated at the top to a few nm depth.

We constructed the depth profile of P(2EHAAA-VAc)/P(VDF-HFA) blends from PASFTIR and ATR-FTIR results. Figure 6 shows the depth profile of the P(2EHA-AA-VAc)/ $\mathrm{P}$ (VDF-HFA) (50/50) blend. Thickness is $30 \mu \mathrm{m}$ and P(VDF-HFA) content calculated with eq 1 was expressed as the integrated surface excess $\phi_{1}$. Depth was calculated by eq 2 and 3. Depths for ATR-FTIR on incidence angle of $30^{\circ}$ and quadrature PAS-FTIR were handled with $4 \mu \mathrm{m}$ and $6 \mu \mathrm{m}$ as the assumption, respectively. We judged that these depths were fitted on the curve of $\phi_{1}$ and depth. The integrated surface excess $\phi_{1}$ decreased with increasing depth, i.e., (1) $\phi_{1}$ decreased exponentially with increasing depth (from surface side to $\sim 10 \mu \mathrm{m}$ depth), (2) The decreasing ratio of $\phi_{1}$ against depth was very little (from $\sim 10 \mu \mathrm{m}$ to $\sim 20 \mu \mathrm{m}$ ), (3) $\phi_{1}$ decreased exponentially with increasing depth (from $\sim 20 \mu \mathrm{m}$ depth to bottom side). Cowie et al. ${ }^{16}$ introduced the integrated surface excess $\phi_{1}$ vs. depth plot as exponential, step, linear, and critically damped $\sin$. In the surface to $\sim 10 \mu \mathrm{m}$ depth and bottom to $\sim 20 \mu \mathrm{m}$ depth for P(2EHA-AA-VAc)/P(VDF-HFA) (50/50) blend, the relationship between $\phi_{1}$ and measuring depth was varied with the exponen- 


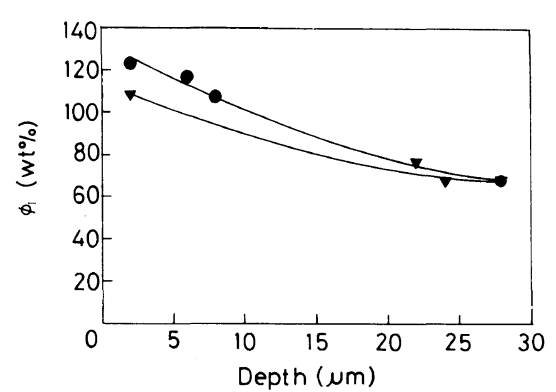

Figure 7 Depth profiles of P(2EHA-AA-VAc)/P(VDFHFA) (30/70), (10/90) blends obtained by ATR-FTIR and PAS-FTIR analyses. Integrated surface excess $\phi_{1}$ of P(VDF-HFA) component versus measuring depth calculated with eqs 2 and 3 . $\phi_{1}$ were calculated by eq 1 . $(10 / 90)$ blend; $\nabla,(30 / 70)$ blend.

tial function. On the contrary, it was suggested that $\phi_{1}$ did not change with depth from $\sim 10 \mu \mathrm{m}$ to $\sim 20 \mu \mathrm{m}$ depth. P(VDF-HFA) content in this region $(10 \sim 20 \mu \mathrm{m}$ depth) was the same as bulk content (about $50 \mathrm{wt} \%$ ). We cannot get this depth profile of $\mathrm{P}(2 \mathrm{EHA}-\mathrm{AA}$ VAc)/P(VDF-HFA) (50/50) blend accurately because $\phi_{1}$ was not obtained in the $10 \sim 20 \mu \mathrm{m}$ depth region. To evaluate $\phi_{1}$ in this region, we should carry out microscopic FTIR analysis. However, the features of $\phi_{1} v s$. depth plot for $(50 / 50)$ blend may be reasonable. We suspect that the characteristic depth profile of $(50 / 50)$ blend is formed by immiscibility, surface tension and density. Figure 7 shows $\phi_{1} v s$. depth plots for P(2EHA-AA-VAc)/P(VDFHFA) (30/70), (10/90) blends. In the measuring region, $\phi_{1}$ decreased with increasing depth linearly. Therefore, PAS-FTIR analysis supposed to be very effective for depth profiling of immiscible polymer blends such as P(2EHAAA-VAc)/P(VDF-HFA) blends.

Figure 8 shows the depth profiles of $\mathrm{P}(2 \mathrm{EHA}-$ AA-VAc)/P(VDF-HFA) (50/50), (30/70), $(10 / 90)$ blends obtained by XPS analysis. The integrated surface excess content of the P(VDFHFA) component was indicated when $W$ was plotted against depth obtained by eq 4 . The surface excess of the P(VDF-HFA) component in $(50 / 50)$ and $(30 / 70)$ blends decreased with

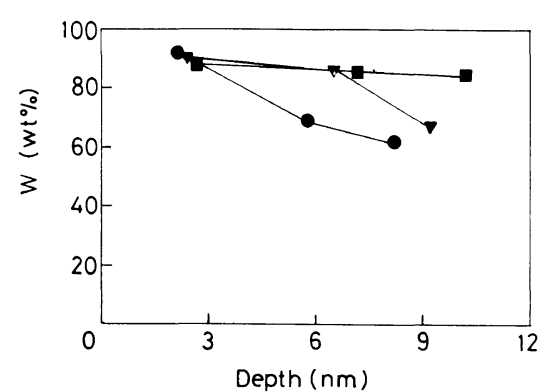

Figure 8. Depth profiles of $\mathrm{P}(2 \mathrm{EHA}-\mathrm{AA}-\mathrm{VAc}) / \mathrm{P}(\mathrm{VDF}-$ HFA) $(50 / 50),(30 / 70)$, and $(10 / 90)$ blends obtained by XPS analysis. Integrated surface excess content $\mathrm{W}$ of P(VDF-HFA) component versus depth calculated with eq 4 . $W$ were calculated by eq $6.0,(50 / 50)$ blend; $\nabla$, (30/70) blend; $\square,(10 / 90)$ blend.

increasing depth, while that in $(10 / 90)$ blends did not change with depth. It is very interesting to compare the XPS results with FTIR results. In $\mathrm{P}(2 \mathrm{EHA}-\mathrm{AA}-\mathrm{VAc}) / \mathrm{P}(\mathrm{VDF}-\mathrm{HFA})(50 / 50)$, (30/70) and (10/90) blends, P(VDF-HFA) concentration in blends obtained from XPS and FTIR results gradually decreased from surface to bottom, respectively. However, $\phi_{1}$ obtained by FTIR were larger than $W$ obtained by XPS. So we noted differences in weight fractions determined from XPS and FTIR. $W$ were calculated from the ratio of fluorine number to carbon number $\mathrm{F} / \mathrm{C}$, while $\phi_{1}$ were calculated with absorbance ratio based on $\mathrm{C}-\mathrm{F}$ absorption and $\mathrm{C}=\mathrm{O}$ absorption. If the $\mathrm{C}=\mathrm{O}$ unit in P(2EHA-AA-VAc) was deeply precipitated at bottom direction, the $\phi_{1}$ values might be higher than $W$ values. We think that the $\mathrm{C}=\mathrm{O}$ unit in $\mathrm{P}(2 \mathrm{EHA}-\mathrm{AA}-\mathrm{VAc})$ was deeply precipitated for $(50 / 50)$ blend. The discrepancy of weight ratio between $W$ and $\phi_{1}$ may be also influenced by the following reasons.

1) Differences in measuring conditions (interface: vaccum/sample for XPS, air/sample for FTIR).

2) Calculation of $\phi_{1}$ (relationship between $I_{870} / I_{1730}$ and $\phi_{1}$ obtained by $\mathrm{KBr}$ tablet may differ from that by ATR-FTIR. Then, the integrated surface excess $\phi_{1}$ cannot 
be calculated by eq 1 ).

As reported previously, ${ }^{1}$ gradient material is influenced by immiscibility and differences in surface tension of components. In general, miscibility between acrylate polymer and fluoro polymer is improved with the side chain length for acrylate polymer. ${ }^{17} \mathrm{We}$ reported that the poly(ethyl acrylate) PEA was miscible with P(VDF-HFA) at room temperature and the lower critical solution temperature (LCST) phase diagram (critical temperature, $200^{\circ} \mathrm{C}$ ) was found by means of DSC thermal analysis and optical microscopy. ${ }^{18}$ If the depth profile of the PEA/P(VDF-HFA) blend is examined with XPS, ATR-FTIR, and PAS-FTIR analyses, the effect of miscibility on surface segregation or gradient material may be evaluated. In addition, it may be possible that the molecular weights, molecular weight distribution and coating substrate influence surface segregation or gradient structure. Further research is necessary to establish the effects of differences in miscible and immiscible blend. Molecular weights, distribution and coating substrate on surface segregation behavior will also be conducted in our future study.

\section{CONCLUSIONS}

In $\mathrm{P}$ (2EHA-AA-VAc)/P(VDF-HFA) immiscible blends, the depth profiles (integrated surface excess of P(VDF-HFA) component $\left(\phi_{1}\right) v s$. detected depth plots) were constructed by ATR-FTIR and PAS-FTIR analyses. In P(2EHA-AA-VAc)/P(VDF-HFA) (50/50), $(30 / 70)$, and $(10 / 90)$ blends, as $\phi_{1}$ decreased with increasing depth, and thus P(2EHA-AAVAc)/P(VDF-HFA) blends may be constructed gradient materials (surface segregation structure). The depth profile of the $(50 / 50)$ blend did not exhibit a simple gradient structure but a sharp gradient on the surfaces and a plateau in the middle position. We found that PAS-FTIR analysis is very effective for the depth profiling in immiscible polymer films such as blends of P(2EHA-AA-VAc) with P(VDF-HFA).

Acknowledgements. The authors express our appreciation to Dr. K. Maeda of Central Glass Co., Ltd. for supplying P(VDF-HFA), and also gratitude Dr. T. Yokoyama of Bio-Rad Lab. Co., Ltd. to his cooperation for PAS-FTIR analysis. The author, Y. Kano is a JSPS research fellow.

\section{REFERENCES}

1. Y. Kano, K. Ishikura, S. Kawahara, and S. Akiyama, Polym. J., 24, 135 (1992).

2. Y. Kano and S. Akiyama, Kobunshi, 41, 774 (1992).

3. H. R. Thomas and J. J. O'Malley, Macromolecules, 14, 1316 (1981).

4. a) R. Chujo, T. Nishi, Y. Sumi, T. Adachi, H. Naito, and H. Frentzel, J. Polym. Sci., Polym. Lett. Ed., 21, 487 (1983).

b) G. Coulon, T. P. Russell, V. R. Deline, and P. F. Green, Macromolecules, 22, 2581 (1989).

5. R. L. Schmitt, J. A. Gardella, Jr., J. H. Magill, L. Salvati, Jr., and R. L. Chin, Macromolecules, 18, 2675 (1985).

6. S. H. Anastasiadis, T. P. Russell, S. K. Satija, and C. F. Majkrzak, J. Chem. Phys., 92, 5677 (1990).

7. K. R. Shull, K. I. Winey, E. L. Thomas, and E. J. Kramer, Macromolecules, 24, 2748 (1991).

8. a) J. J. Schmidt, J. A. Gardella, Jr., and L. Salvati, Jr., Macromolecules, 22, 4489 (1989). b) J. M. G. Cowie, B. G. Devlin, and I. J. McEwen, Polymer, 34, 501 (1993).

9. Y. Kano, S. Akiyama, and T. Kasemura, J. Appl. Polym. Sci., 50, 1619 (1993).

10. R. M. Dittmar, J. L. Chao, and R. A. Palmer, Appl. Spectrosc., 45, 1104 (1991).

11. Y. Kano, K. Ishikura, and S. Akiyama, Nippon Setchaku Gakkaishi, 26, 252 (1990).

12. S. Kobayashi, R. Saito, T. Nakano, T. Yokoyama, Y. Kano, and S. Akiyama, "Bunsekikiki to Kaisekishisutemu ni Kansuru Touronkai Kouen Youshishu”, The Analytical Chemical Society of Japan, Tokyo, 1993, 1 B13.

13. Y. Kano and S. Akiyama, Nippon Setchaku Gakkaishi, 26, 367 (1990).

14. T. Kasemura, Y. Okada, and M. Fujii, Nippon Setchaku Gakkaishi, 26, 106 (1990).

15. J. C. Ashley, J. Electron Spectr., 28, 177 (1982).

16. J. M. G. Cowie, B. G. Devlin, and I. J. McEwen, Macromolecules, 26, 5628 (1993).

17. K. Maeda, S. Tasaka, and N. Inagaki, Kobunshi Ronbunshu, 47, 985 (1990).

18. Y. Kano and S. Akiyama, Polym. Bull., 29, 97 (1992). 